\title{
Smoke Transport and FDS Validation
}

\author{
DANIEL GOTTUK, CHRISTOPHER MEALY and JASON FLOYD \\ Hughes Associates, Inc. \\ 3610 Commerce Drive, Suite 817 \\ Baltimore, Maryland 21227
}

\begin{abstract}
A 2006 Fire Protection Research Foundation (FPRF) project used the NIST Fire Dynamics Simulator to investigate smoke detector spacing for spaces with deep beam pockets and level ceilings. One configuration evaluated in this research was a corridor configuration with varying beam depth, beam spacing, corridor width, and ceiling height. A subset of the modeled corridor configurations was conducted with full-scale experiments to validate the findings of the modeling study. This paper presents the findings of the experimental validation and new discoveries regarding smoke production and loss mechanisms that have an impact on modeling of fires and the spread of smoke. The temperature and velocity measurements along the corridor ceiling were consistent with the modeling results. However, the study showed that FDS significantly over-predicted smoke concentrations compared to the experiments. Exploratory findings indicate that soot deposits to the ceiling above the plume may be as high as 37 percent of the soot produced. Current versions of FDS do not account for this substantial soot loss. The work also revealed that there is a large discrepancy between reported small-scale soot yields and larger scale fires.
\end{abstract}

KEYWORDS: modeling, detection, CFD, smoke, experiments, FDS, soot yield

\section{INTRODUCTION}

A 2006 Fire Protection Research Foundation (FPRF) project [1] used the NIST Fire Dynamics Simulator, version $4[2,3]$, to investigate smoke detector spacing for spaces with deep beam pockets and level ceilings. One configuration evaluated in this research was a corridor configuration with varying corridor widths of

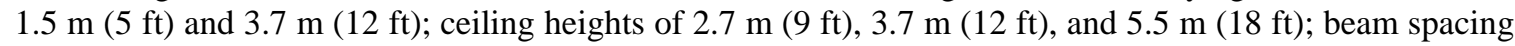

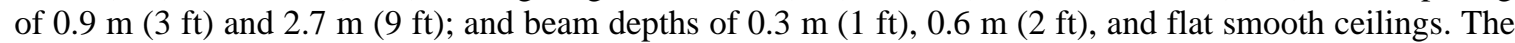
beams were modeled as $0.15 \mathrm{~m}$ (6 in.) thick obstructions and all surfaces were modeled with properties of concrete. A multi-block grid was utilized in which $38 \mathrm{~mm}$ (1.5 in.) cells were used around the fire plume and along the ceiling to capture the flow between and below beams. A courser grid of $152 \mathrm{~mm}(6 \mathrm{in}$.) cells was used for the rest of the domain. An illustration of the simulation domain with grid overlay is presented in Fig. 1. The results of a grid sensitivity study indicated the appropriateness of the selected grids.

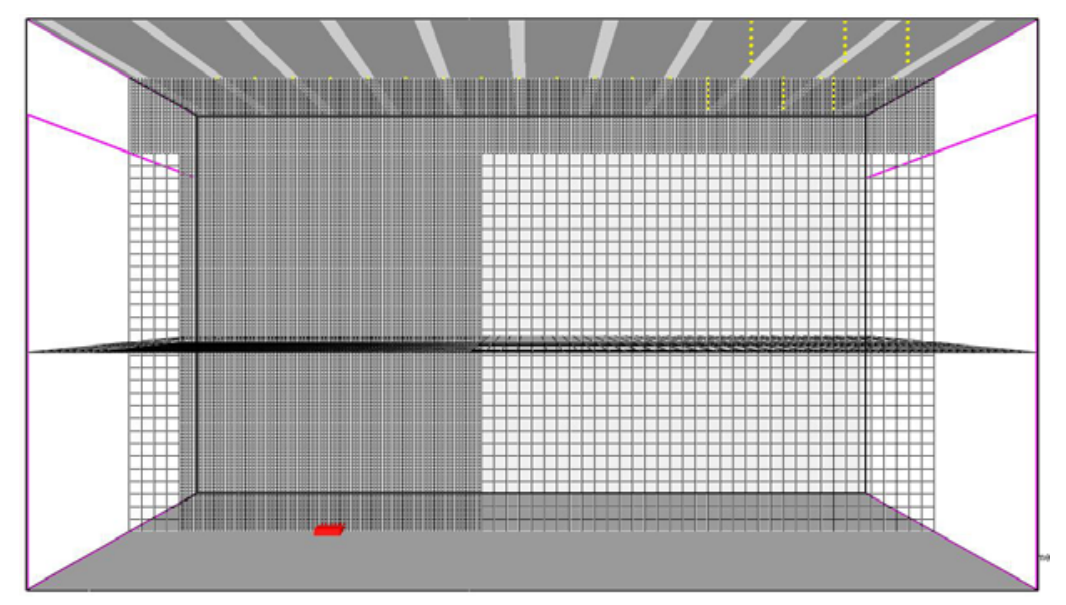

Figure 1. Illustration of Corridor Configuration and Grid Mesh used in the Modeling Study. 
The model runs used an instantaneous $100 \mathrm{~kW}$ fire centered between beams under the corridor ceiling. The base of the fire was $0.31 \times 0.31 \mathrm{~m}(1 \mathrm{x} 1 \mathrm{ft})$ and was located on the floor. The soot yield of the fire was 0.022 grams per gram of fuel. Temperature prediction points and smoke detectors were positioned down the centerline of the corridor at the bottom of beams and centered in the beam bays on the ceiling.

In this project, a subset of the modeled corridor configurations was used in full-scale experiments to validate the findings of the modeling study. This paper presents the findings of the experimental validation and new discoveries regarding smoke production and loss mechanisms that have an impact on modeling of fires and the spread of smoke.

\section{OBJECTIVE}

The primary objective of this work was to document the response times of smoke detectors installed in varying corridor configurations with beams relative to an open smooth ceiling detector response and to compare the relative responses with the results of the previous modeling study [1]. A second objective was to provide a direct comparison of fire conditions (temperature, velocity, smoke) and smoke detector responses with the specific output of the modeling study. This paper addresses the results of the second objective focused on model validation.

\section{APPROACH}

To validate the modeling, a highly variable apparatus was designed and used for conducting full-scale experiments replicating a large subset of the corridor modeling runs. The corridor apparatus was able to be configured to almost all of the combinations of variables evaluated in the modeling study. For this paper, the discussion is focused on only the $3.7 \mathrm{~m} \mathrm{(12} \mathrm{ft)} \mathrm{wide} \mathrm{corridor} \mathrm{with} \mathrm{no} \mathrm{beams} \mathrm{(smooth} \mathrm{ceiling)} \mathrm{and} \mathrm{with}$

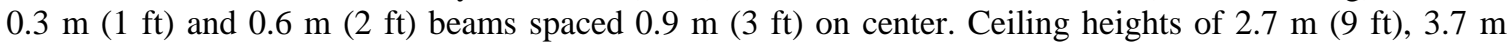
$(12 \mathrm{ft})$, and $5.5 \mathrm{~m}(18 \mathrm{ft})$ were evaluated.

The tests consisted of burning a fire centered lengthwise in the corridor so that smoke detectors, spaced from the fire in both directions down the corridor, were uniformly exposed. The baseline condition consisted of smoke detectors on a smooth, open ceiling (i.e., no walls or beams) spaced at the typical industry practice of $84 \mathrm{~m}^{2}\left(900 \mathrm{ft}^{2}\right)$ per detector, which equates to $9.1 \mathrm{~m}(30 \mathrm{ft})$ between detectors. Therefore, the baseline detector response (smooth ceiling response) was the response time of ceiling-

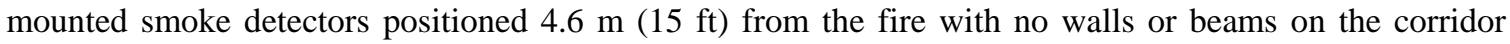
apparatus; this is discussed further in the results.

\section{Experimental Apparatus and Instrumentation}

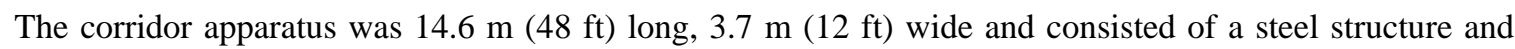
$6.35 \mathrm{~mm}(0.25 \mathrm{in}$.) gypsum wall board (GWB). The corridor had $6.35 \mathrm{~mm}$ GWB walls extending $1.2 \mathrm{~m}$ $(4 \mathrm{ft})$ below the ceiling. The remainder of each wall extending to the floor was constructed from $0.1 \mathrm{~mm}$ (4 mil) polyethylene plastic sheeting. Corridor beams were constructed from steel stud framing and $6.35 \mathrm{~mm}$ (0.25 in.) GWB. The beams were $0.15 \mathrm{~m}$ (6 in.) thick and either $0.3 \mathrm{~m}(1 \mathrm{ft})$ or $0.6 \mathrm{~m}(2 \mathrm{ft})$ deep.

Figure 2 shows a diagram of the corridor apparatus with the beams in place, and Fig. 3 shows a photograph of the test setup. The figure presents the locations of spot smoke detectors, optical density meters and velocity probes. At every detector location, there was a $24 \mathrm{Ga}$, Type $\mathrm{K}$, bare-bead thermocouple positioned $19 \mathrm{~mm}$ (0.75 in.) from the ceiling, beam, or wall surface that it was mounted on. Most devices were centered down the corridor on the ceiling or the bottom of a beam, except for a number of devices mounted to the wall, as shown by the symbols near the walls in Fig. 2.

Optical density meters were constructed in general accordance with the specifications of UL 268. [4] The optical density meters used were comprised of a 6V General Electric sealed beam light source, and a Huygen Model 856 RRV, photovoltaic cell. The path length for all ceiling mounted ODM's was $1.52 \mathrm{~m}$ $(5 \mathrm{ft})$. In order to accommodate the installation of beams within the corridor, it was necessary to decrease the path length of the wall-mounted ODM. This ODM had a path length of $0.6 \mathrm{~m}(2 \mathrm{ft})$. 


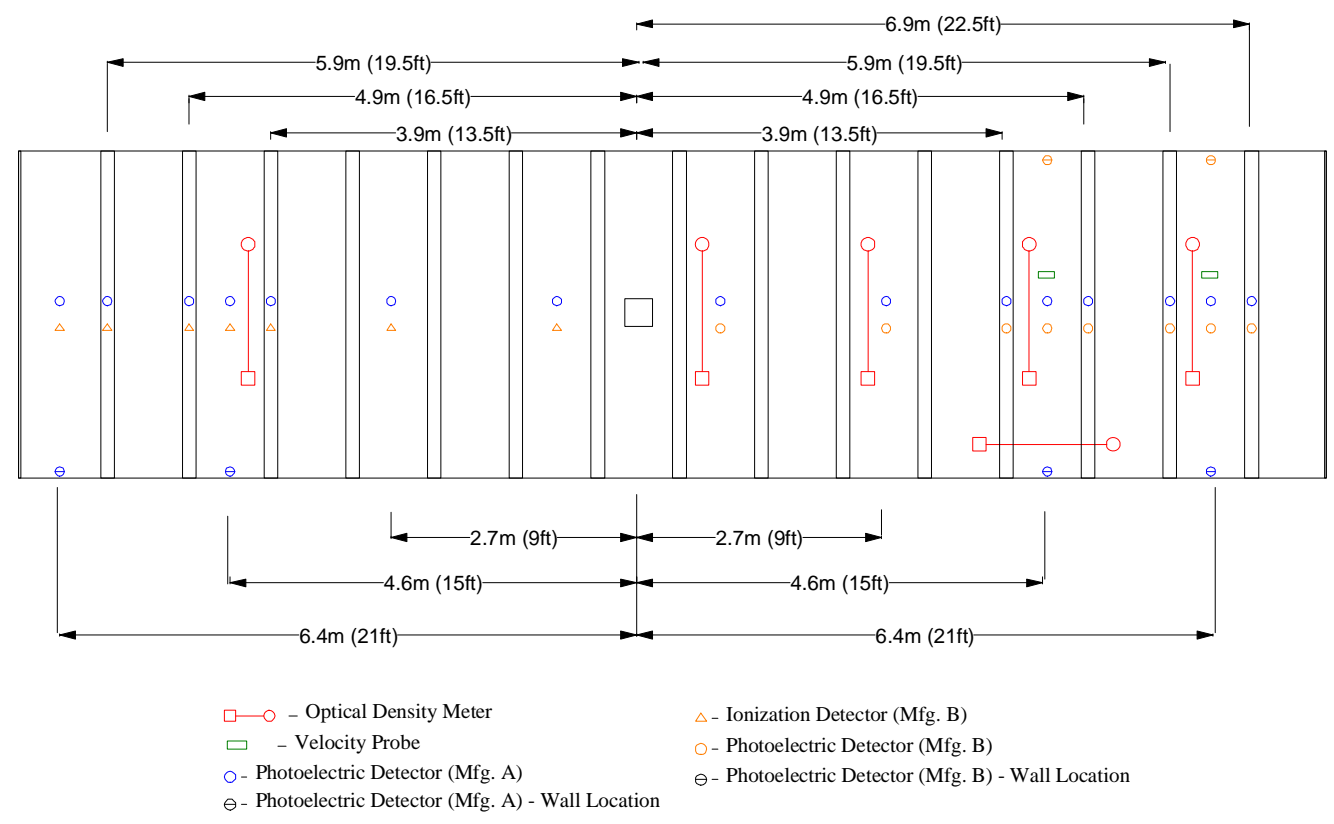

Fig. 2. Diagram of corridor test apparatus with instrumentation.



Fig. 3. Photograph of corridor test apparatus with instrumentation.

Velocity measurements were collected at two locations using Applied Technologies Sonic Anemometer/Thermometer Model SPA5/2Y (courtesy of NIST). The velocity probes were located in the


measure velocities in both the longitudinal and lateral directions. They were installed such that velocities were measured approximately $19 \mathrm{~mm}$ ( $0.75 \mathrm{in}$.) from the ceiling of the corridor. The velocity probes were capable of measuring velocities ranging from $0-10 \mathrm{~m} / \mathrm{s}$ with a resolution of $0.01 \mathrm{~m} / \mathrm{s}$.

Two different spot detection technologies (i.e., ionization, photoelectric) from two different manufacturers were installed within the corridor. Smoke detector clusters were installed on the ceiling of the corridor, on beam bottoms, and at various elevations along the walls of the corridor. Detector clusters installed on the 


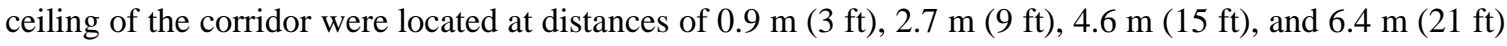
from the fire source in both directions. Clusters installed on the bottoms of beams were located at distances

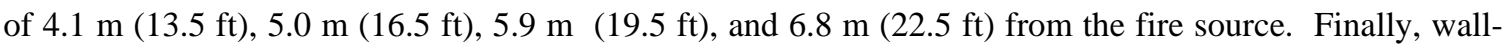

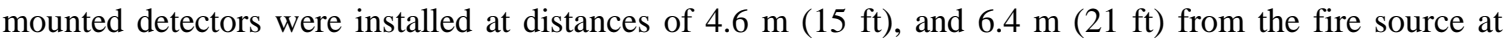

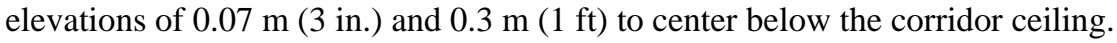

Photoelectric detectors from the same manufacturer (Mfg A) were installed at all locations along the length of the corridor as well as on the walls of the corridor. The installation of the same technology from the same manufacturer on both sides of the fire source provided a means of verifying corridor symmetry. Photoelectric detectors from Manufacturer B were installed on the right hand side (RHS) of the corridor and ionization detectors from Manufacturer B were installed on the left hand side (LHS). The installation of the same detector technology (i.e., photoelectric) from two different manufacturers on the same side of the corridor (i.e., RHS) provided a means of assessing whether the results of the study were independent of manufacturer. Furthermore, the installation of different detector technologies (ion and photo) on the same side of the corridor (i.e., LHS) provided a means of evaluating the different detector technologies when subjected to comparable exposures.

The photoelectric detectors provided by both Manufacturers A and B were set to an alarm threshold of 2.5 percent obscuration per foot and the ionization smoke detectors provided by Manufacturer B were set to an alarm threshold of 1.2 percent obscuration per foot. Detector activation for Manufacturer B devices was via panel activated I/O modules that were monitored as normally-open relays by the data acquisition system which recorded a step change in voltage for each individual detector activation. Detector outputs for Manufacturer A devices were collected using an independent data logger and post-processing routine. This system allowed post-test evaluation of alarms at any user-selected sensitivity setting.

\section{Exposure Fire}

The fire source in this test series was centrally located beneath the corridor as shown in Fig. 2 to allow a larger data set of detector responses to be collected for each test conducted. The burner was laterally centered beneath the corridor ceiling and located beneath the central most beam bay of the corridor. The burner was not geometrically centered in the longitudinal direction due to the fact that in the previous modeling research [1], the burner was centered beneath a beam bay, whereas the geometric center of the test corridor falls directly on a beam.


used an instantaneous, constant $100 \mathrm{~kW}$ fire with a base of $0.31 \times 0.31 \mathrm{~m}$ and a soot yield of 2.2 percent (i.e., $0.022 \mathrm{~g} / \mathrm{g}$ ). The burner was constructed in general accordance with the requirements of Annex A of ISO 9705 [5]. Based on data for overventilated fires [6], a propane fire source was expected to produce a 2.4 percent soot yield. Hood calorimetry tests were conducted with the 0.31 x $0.31 \mathrm{~m}$ sand burner propane fires to verify both the heat release rate (HRR) and the soot yield. However, the results showed that for a $100 \mathrm{~kW}$ propane fire, the measured soot yield was 0.41 percent with a standard deviation of 0.09 . The soot yield was calculated based on optical density measurements made via a white light optical density meter and a specific extinction coefficient of $8.71 \mathrm{~m}^{2} / \mathrm{g}$. The measured soot yield of 0.41 percent is approximately one-fifth of the value reported by Tewarson [6] for bench-scale, overventilated propane fires. Consequently, a second fuel with a higher reported soot yield was selected for evaluation: ethylene with a soot yield of 4.3 percent [6]. The measured soot yield for the ethylene fires was an average of 2.0 percent with a 0.16 percent standard deviation. This measured value is approximately one-half of the reported value [6]. Since the measured soot yield of $2+0.2$ percent was relatively close to the 2.2 percent used in the modeling study, ethylene was selected for the initial detection tests. The comparison between the experimental ethylene fire tests and the modeling is discussed below in the results.

However, after the initial ethylene fire detection tests were conducted for the baseline smooth ceiling case (i.e., without walls or beams), it was found that the $100 \mathrm{~kW}$ ethylene fires did not cause alarm conditions for the smoke detectors at the $4.6 \mathrm{~m}(15 \mathrm{ft}$ ) distance from the fire (i.e., $30 \times 30 \mathrm{ft}$ coverage) for a number of ceiling heights. Since the study is based on a comparison of detector response with beamed ceilings compared to the smooth ceiling case, it was a necessity that the $4.6 \mathrm{~m}(15 \mathrm{ft})$ detectors on the smooth ceiling reach alarm conditions. Consequently, a third fuel with a higher soot yield was investigated for use; propylene with a reported yield of 9.5 percent [6]. Similar to the ethylene fires, the propylene fires had a 
measured average soot yield that was half of the value reported by Tewarson [6] (i.e., 4.8 percent with a 0.36 percent standard deviation compared to $9.6 \%$ ). The $100 \mathrm{~kW}$ propylene fires were sufficient to cause alarms at all the detector locations for all smooth ceiling heights. Although the measured soot yield for propylene (4.8 percent) was larger than that used in the previous modeling (2.2 percent) [1], the need to have baseline detectors respond resulted in the use of propylene for all the tests. This issue is discussed further in the results.

The difference between the measured soot yields for the $100 \mathrm{~kW}$ fires and those reported in the literature by Tewarson [6] ranged from a factor of 2 to 5. The yield difference is expected to be a result of the differences in scale of the fires used by Tewarson versus the $100 \mathrm{~kW}$ fires used in this study. Tewarson reports soot yield data obtained from the ASTM E2058 fire propagation apparatus, a bench-scale apparatus with fire sizes on the order of several kilowatts [6,7]. Several authors have noted issues with scale and the production of soot. Pitts and Mulholland reported that smoke yields for propane fires decreased with increasing fire size [8]. The range of yields noted is 0.0106 to 0.0052 . The trend identified by Pitts and Mulholland is consistent with the results of this study. The discrepancy between measured soot yields for various scale fires and the selection of yields as model inputs certainly deserves renewed attention and research, particularly as advances are made in modeling visibility and smoke detector response.

\section{RESULTS AND DISCUSSION}

The following sections provide an overview of the key findings from this study that address the validation of gas and smoke transport by the model. Additional results and details can be found in the full report from the Fire Protection Research Foundation [REF X insert b/n 8 and 9]. The full report discusses the comparison of experimental smoke detector responses versus model predictions to a greater extent than covered in this paper which is focused more on the selection/modeling of the soot yield and transport of smoke for the purpose of smoke detector modeling.

\section{Symmetry of Corridor Tests}

As shown in Fig. 2, the fire was located near the center of the corridor so that multiple detectors could be equally exposed on both ends of the corridor. To assure that this experimental setup closely matched the model, the symmetry of the apparatus was assessed by comparing the conditions at both ends of the

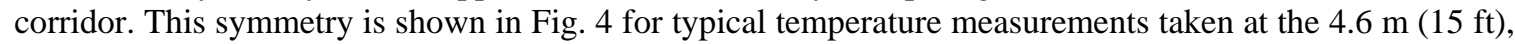

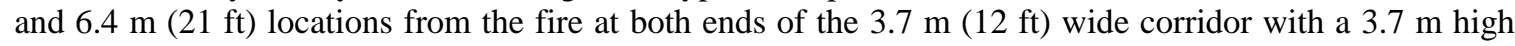
ceiling. The temperature profiles at both ends of the corridor agree very well, within the $2.2^{\circ} \mathrm{C}$ uncertainty of the thermocouple measurements. On average, this trend was observed for all of the ceiling configurations. Figure 5 shows the corresponding smoke measurements for the same test in Fig. 4. The smoke optical density agrees very closely, particularly in the early time frame of up to 30 to 60 seconds, within which detection typically occurred.

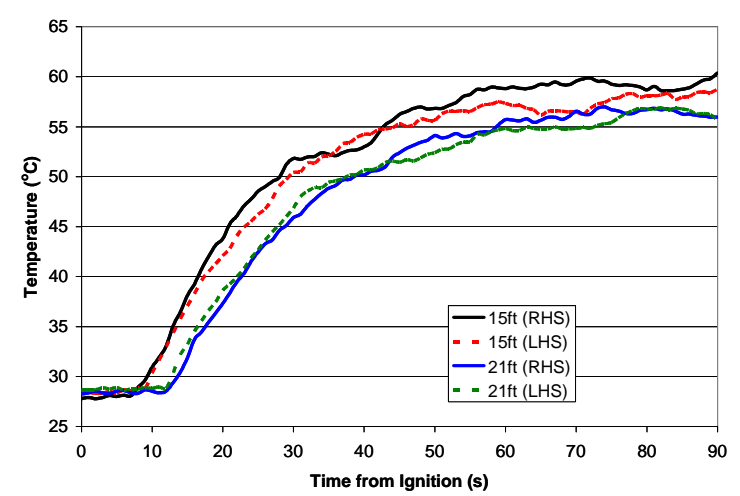

Fig. 4. Symmetrical temperature measurements at both ends of corridor.

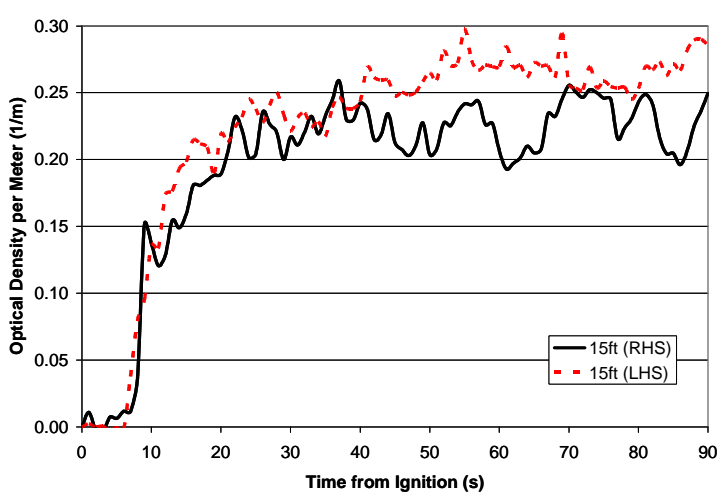

Fig. 5. Symmetrical smoke optical density measurements at both ends of corridor. 


\section{Unconfined Smooth Ceiling Response}

As noted above, the baseline condition consisted of smoke detectors on a smooth, open ceiling (i.e., no walls or beams) spaced at the typical industry practice of $84 \mathrm{~m}^{2}\left(900 \mathrm{ft}^{2}\right)$ per detector, which equates to $9.1 \mathrm{~m}$ (30 ft) between detectors. Ideally to measure the baseline detector response, detectors should be mounted at the $9.1 \mathrm{~m} \times 9.1 \mathrm{~m}(30 \mathrm{x} 30 \mathrm{ft})$ spacing on an open ceiling that extends beyond the devices. The

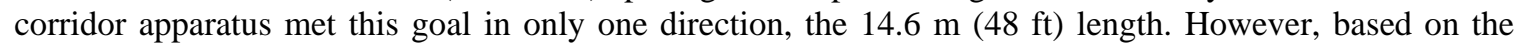
plume width at the ceiling and the radially uniform dispersion of the ceiling jet, the width of the ceiling apparatus (3.7 m (12 ft)) was deemed to have no effect on the ceiling jet properties down the length of the ceiling. Assuming a plume angle of 15 degrees [9,10], the plume diameter at the ceiling for the $5.5 \mathrm{~m}$ $(18 \mathrm{ft})$ height is $1.4 \mathrm{~m}(4.7 \mathrm{ft})$. The $5.5 \mathrm{~m}$ high ceiling corresponds to the largest plume impingement area for the conditions tested. In this configuration, the impingement diameter is about 40 percent of the ceiling width.

A FDS 5 model (beta version) [11] was constructed to replicate the smooth corridor ceiling apparatus with no walls. The model was used to compare the open ceiling test apparatus to an ideal condition where the

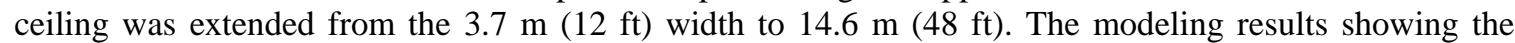
comparison between the narrow and large ceiling configurations exposed to a $100 \mathrm{~kW}$ fire are shown in Fig. 6. Figure 6a shows that the temperature profiles at $4.6 \mathrm{~m}(15 \mathrm{ft})$ from the fire, representing the $9.1 \mathrm{~m} \mathrm{x} 9.1 \mathrm{~m}(30 \mathrm{x} 30 \mathrm{ft})$ detector spacing, agree very well. The corresponding results for smoke optical density are shown in Fig. 6b. These results demonstrate that the open, smooth ceiling experiments can be compared with confidence to the ideal baseline conditions modeled in the 2006 study [1].

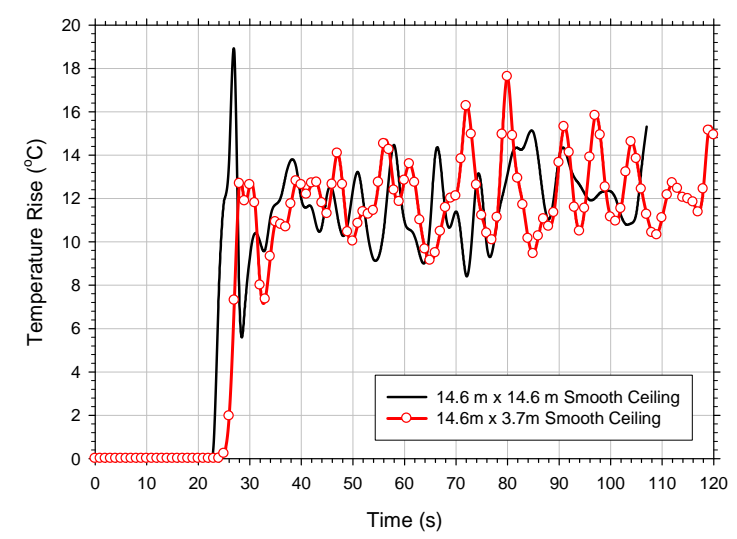

Fig. 6a. Comparison of predicted temperatures at $4.6 \mathrm{~m}$ from the fire for a $2.7 \mathrm{~m}$ high, $14.6 \mathrm{~m}$ long open, smooth ceiling with a $3.7 \mathrm{~m}$ width versus a $14.6 \mathrm{~m}$ width.



Fig. 6b. Predicted smoke level at $4.6 \mathrm{~m}$ from the fire for a $2.7 \mathrm{~m}$ high, $14.6 \mathrm{~m}$ long open smooth ceiling with a $3.7 \mathrm{~m}$ width versus a $14.6 \mathrm{~m}$ width.

\section{Impact of Fire Source Soot Yield - Ethylene Fires}

As noted above, the measured soot yield for the $100 \mathrm{~kW}$ ethylene fires was $2.0 \pm 0.2$ percent, which was within ten percent of the 2.2 percent yield used in the 2006 modeling study [1]. The uncertainty of the fire size was \pm 5 percent. Three initial tests were conducted with ethylene fires under the open, smooth ceiling, one for each of the three heights. Fig. 7 shows a comparison of the measured and the 2006 model predicted temperature rise (i.e., the change in temperature above the initial condition) at $4.6 \mathrm{~m}$ (15 ft) from the fire for


temperature for the first half of a minute, but then levels out to a steady-state value that agrees well with the model. The uncertainty in the temperature comparisons is estimated to be $3^{\circ} \mathrm{C}$ based on the uncertainties in thermocouple measurements, the heat release rate and the subsequent effect on plume ceiling temperature calculations. 
The experimental temperature lag compared to the predicted values in the beginning of the test is potentially a result of several factors. One such factor is that FDS does not model a boundary layer and may slightly overestimate the heat transfer to the wall-adjacent cells (i.e., where the temperature is measured) during the initial development of the layer. Other factors may include slight thermal property differences between concrete as used in the 2006 model and gypsum wall board used in the experiments. As will be seen below for various corridor configurations, the comparison of predicted and measured velocity and smoke data do not show a transient lag similar to the initial temperature development. These observations, with the fact that the time from ignition to a measurable temperature rise agrees well between the model and experimental values, further indicates that the thermal balance at the ceiling is the primary reason for the initial 30 second convergence period.

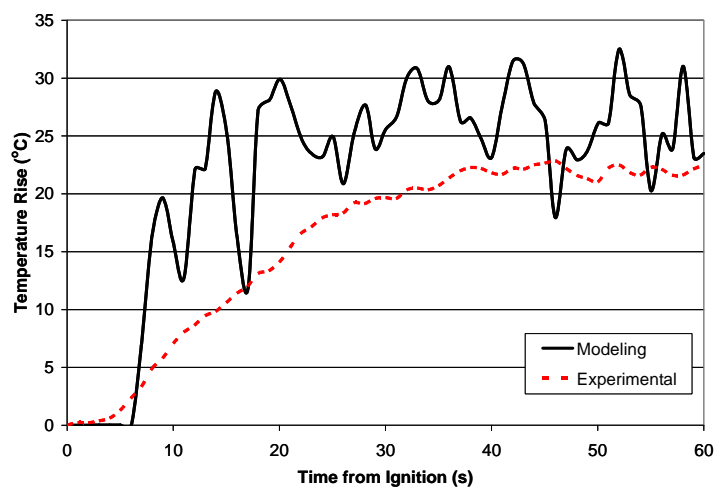

Fig. 7a. Measured and predicted temperature rise at $4.6 \mathrm{~m}$ from the fire for the $2.7 \mathrm{~m}$ high open, smooth ceiling exposed to a $100 \mathrm{~kW}$ ethylene fire.

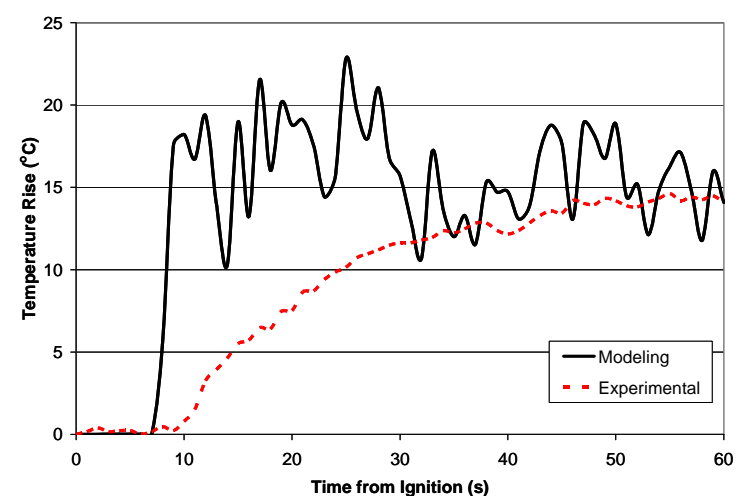

Fig. 7b. Measured and predicted temperature rise at $4.6 \mathrm{~m}$ from the fire for the $3.7 \mathrm{~m}$ high open, smooth ceiling exposed to a $100 \mathrm{~kW}$ ethylene fire.

The measured and predicted smoke optical densities are shown in Fig. 8 for the same ethylene test and model conditions shown in Fig. 7. The plots show that the predicted smoke optical density is two to three times greater than the measured values for the 2.7 and $3.7 \mathrm{~m}$ high ceilings. For the $5.5 \mathrm{~m}$ (18 ft) high ceiling (not shown), the difference between measured and predicted values is 0.015 versus $0.07 \mathrm{~m}^{-1}$. This large difference in smoke concentration is also consistent with the smoke detector responses obtained experimentally compared to the model predictions. Per the model, all baseline detectors (i.e., at the $4.7 \mathrm{~m}$ location) for the 2.7 and $3.7 \mathrm{~m}$ high ceilings alarmed; this was not true for the fire tests, consistent with the lower measured smoke levels in the tests compared to the model. In the tests at the $2.7 \mathrm{~m} \mathrm{(9} \mathrm{ft)} \mathrm{ceiling}$ height, all the detectors on the ceiling alarmed except for one photoelectric unit. At the $3.7 \mathrm{~m}(12 \mathrm{ft})$ ceiling

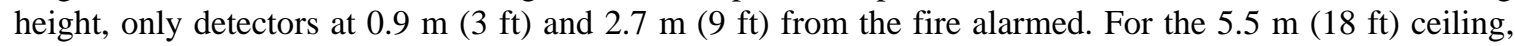
only the detectors at the $0.9 \mathrm{~m}$ location alarmed.

\section{Soot Transport and Deposition}

Since the ethylene fires were unable to provide sufficient smoke to activate the smoke detectors, the majority of tests were conducted with propylene, which had a higher average measured smoke yield of $4.8+0.36$ percent. Preliminary results from the propylene fire tests revealed that substantial soot loss occurred between the source and the various smoke detector locations. This result becomes evident via comparisons of the $100 \mathrm{~kW}$ propylene fire experimental conditions and the 2006 model predictions for a $100 \mathrm{~kW}$ fire with a 2.2 percent smoke yield. Figs. 9a to 9d show the comparison between the measured and



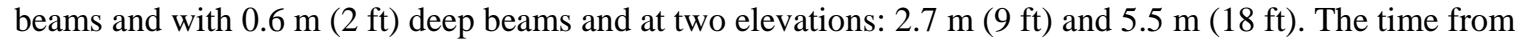
ignition (time $=0 \mathrm{~s}$ ) to the time of initial temperature rise agrees very well between the modeling and experiments. This agreement shows that FDS is accurately predicting the transport of the ceiling jet gases for the varied corridor configurations with the multiple ceiling heights and beam depths. Similar to the comparisons shown in Fig. 7, the predicted temperatures rise sharply compared to the measured values. As 
quasi-steady and steady-state values are reached, the predicted temperatures converge with the measured values, typically within 60 seconds of when the temperature starts to rise.

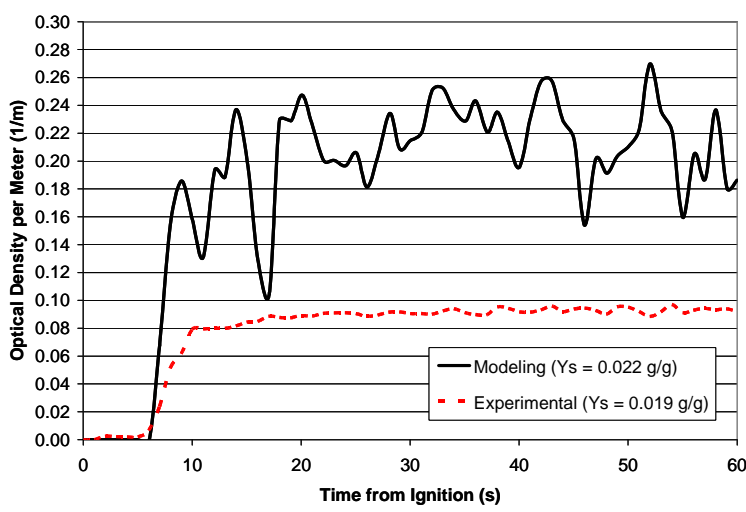

Fig. 8a. Measured and predicted smoke optical density at $4.6 \mathrm{~m}$ from the fire for the $2.7 \mathrm{~m}$ high open, smooth ceiling exposed to a $100 \mathrm{~kW}$ ethylene fire.
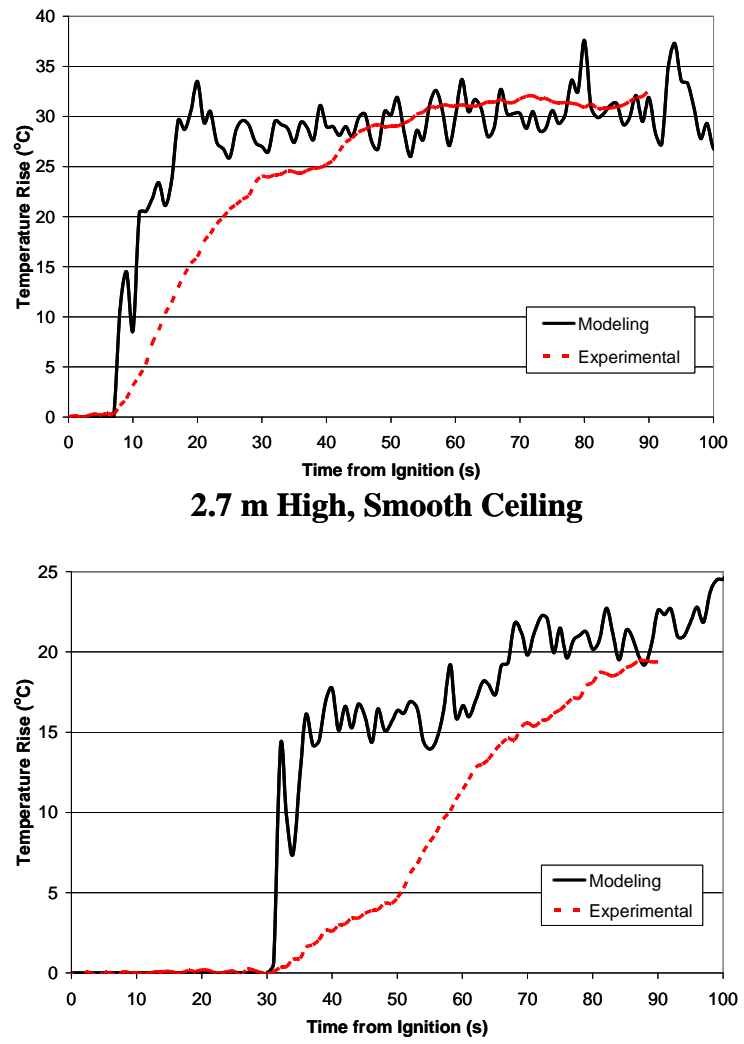

2.7 m High, 0.6 m Beams

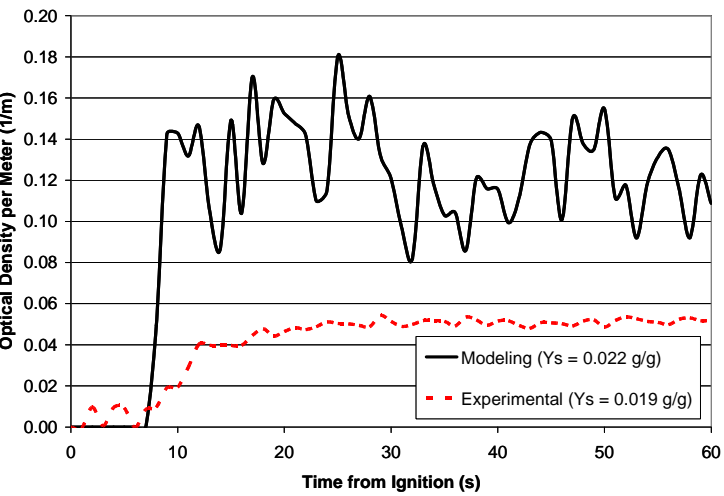

Fig. 8b. Measured and predicted smoke optical density at $4.6 \mathrm{~m}$ from the fire for the $3.7 \mathrm{~m}$ high open, smooth ceiling exposed to a $100 \mathrm{~kW}$ ethylene fire.
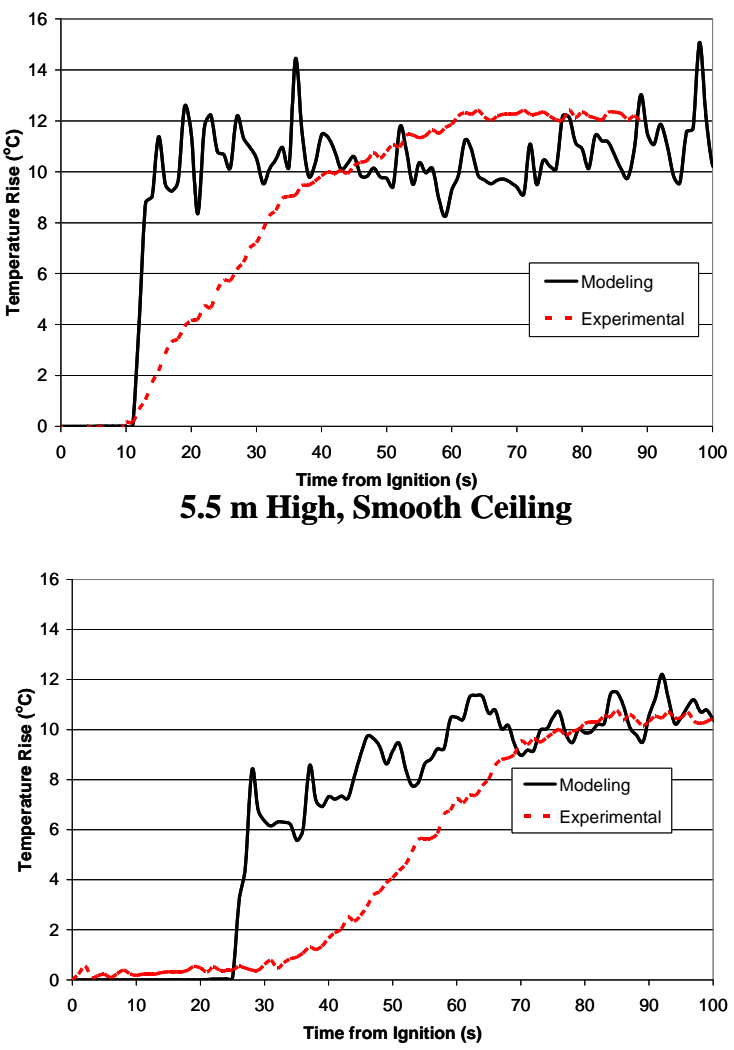

5.5 m High, 0.6 m Beams

Fig. 9. Measured and predicted temperature rise at $4.6 \mathrm{~m}$ from the $100 \mathrm{~kW}$ fire for the $3.7 \mathrm{~m}(12 \mathrm{ft})$ wide corridor with no beams and with $0.6 \mathrm{~m}$ deep beams. 
Figure 10 shows the comparison between the measured and predicted velocity at the $4.6 \mathrm{~m}(15 \mathrm{ft})$ detector

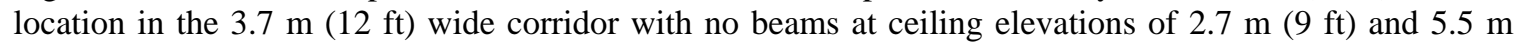
$(18 \mathrm{ft})$. These are the same tests as shown in Fig. 9. The measured and predicted velocities agree well.

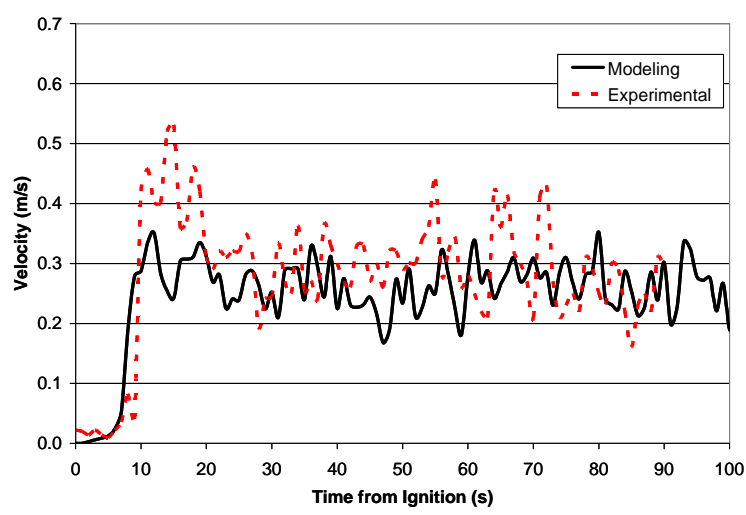

(a). ceiling elevation of $2.7 \mathrm{~m}(9 \mathrm{ft})$.

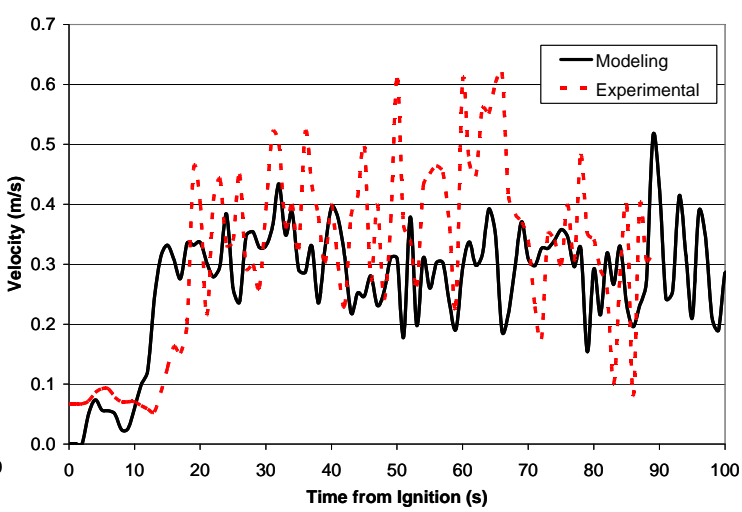

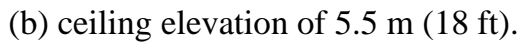

Fig. 10. Measured and predicted velocities at $4.6 \mathrm{~m}$ from the $100 \mathrm{~kW}$ fire for the $3.7 \mathrm{~m}(12 \mathrm{ft})$ wide corridor with no beams at ceiling elevations of $2.7 \mathrm{~m}(9 \mathrm{ft})$ and $5.5 \mathrm{~m}(18 \mathrm{ft})$.

Figure 11 presents the smoke optical density measurements compared to the 2006 model predictions for the same tests shown in Fig. 10. The time from ignition to the time of initial smoke rise agrees well between the modeling and experiment results. The transient trends and smoke levels for each of the ceiling heights track well between the model and experiments. The predicted and measured steady-state smoke levels differ within approximately 20 percent.

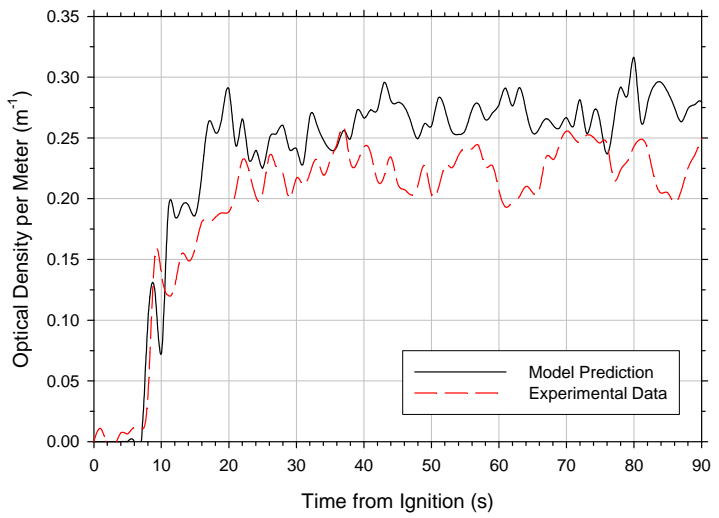

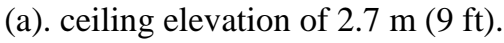



(b) ceiling elevation of $5.5 \mathrm{~m}(18 \mathrm{ft})$.

Fig. 11. Measured (from propylene fire with 4.8\% smoke yield) and predicted (with $2.2 \%$ yield) smoke

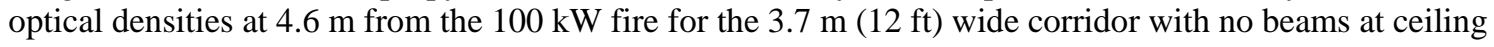

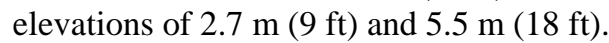

Although the comparison of predicted and experimental smoke concentrations is relatively close, it is important to recall that the model input was a fire with a soot yield of 2.2 percent and the experimental tests used a fire with a soot yield of 4.8 percent, over twice the value. Based on this yield difference and the build up of soot on the ceiling above the fire plume, it became apparent that soot loss was a substantial phenomenon that had to be considered. Although soot deposition in fires is a recognized event, most models are used with an assumption that the degree of soot deposition is relatively small compared to the amount transported in the fire plume and ceiling jets [12]. 
In order to assess the degree of soot loss in the propylene fire experiments, a set of fire tests were conducted with measurements of soot deposition on the ceiling above the plume. After several trials of various measurement techniques, a procedure was selected consisting of soot mass measurements on 6.35 mm (0.25 in.) gypsum wall board (GWB) panels. The GWB panels were selected to replicate the physical and thermal boundary conditions present during actual testing. The panels were $0.3 \mathrm{~m}$ by $0.6 \mathrm{~m}$ in area. Based on the initial trials, it was learned that the sample panels needed to be dried before use to avoid mass loss during the fire test due to elevated plume temperatures driving off water mass from the GWB. Therefore, the GWB samples were conditioned in a convective laboratory oven for 70 minutes at $105^{\circ} \mathrm{C}$ $\left(221^{\circ} \mathrm{F}\right)$. This conditioning resulted in an average reduction in mass of 6 percent ( $80 \mathrm{~g}$ of water driven out). After conditioning, a pair of panels was removed from the oven and quickly taken into the laboratory. One panel was installed on the ceiling centered above the fire, and exposed to the fire plume for a period of 5 minutes. The remaining panel, was used as a control and was placed at floor level in the laboratory for the same duration of time as the ceiling sample. The control panel was used to assess the amount of water absorption that could occur from exposure to the general lab environment. Total time in the laboratory for the GWB panels was 10 minutes. During this time, the average absorption of moisture on the control panels for the various trials was measured to be $2.2 \pm 0.2 \mathrm{~g}$ using a scale with a $0.1 \mathrm{~g}$ resolution. This mass was accounted for when evaluating the mass of the panels before and after exposure. The presence of water vapor in the fire plume and the potential influence of this on post-test mass measurements were also considered in these exploratory tests. However, given that average gas temperatures at the surface of the substrate for the 2.7 and $3.7 \mathrm{~m} \mathrm{(9}$ and $12 \mathrm{ft}$ ) ceiling heights were $112^{\circ} \mathrm{C}$ and $92^{\circ} \mathrm{C}$, respectively, absorption of water vapor by the ceiling mounted panel was expected to be insignificant during the relatively brief 5 minute exposure at the elevated temperature.

The mass of soot collected on each ceiling mounted panel was calculated as the difference of the post- and pre-fire mass measurements and the subtraction of fifty percent of the measured mass gain from water absorption measured on the control panel. The subtraction of fifty-percent of the water absorption measured in the control sample is supported by the fact that the ceiling sample panel was exposed to hot fire gases for only five of the ten minutes during which the control sample was in the lab. Furthermore, any water absorbed by the sample panel prior to the fire would most likely be driven out by the exposure to hot fire gases. Therefore, one can assume that the sample panel may not experience water gain until after the fire was terminated, that is, approximately one-quarter of the control sample water gain. Though using onequarter may be bounding (i.e. result in higher soot loss), the use of one-half of the water gain was deemed reasonable since other assumptions would result in lower soot deposition calculations. The bounding water absorption assessment is counterbalanced by the fact that the panel on the ceiling only collected soot in the center of the circular impact zone of the plume on the ceiling (i.e., the panel was only a fraction of the entire visible deposition area on the ceiling). This central sample area may have a higher soot deposition flux relative to the total deposition area. For this scoping study, it was assumed that the deposition rate on the ceiling panel was uniform across the whole circular plume impingement area on the ceiling. The impingement area was calculated at each ceiling height based on a plume angle of 15 degrees [9,10].

Using the calculated impingement areas and the soot deposition flux determined for the sample panels, soot losses of $11.9 \mathrm{~g}$ and $10.1 \mathrm{~g}$ were calculated for the exposure fire impinging on a $2.7 \mathrm{~m}(9 \mathrm{ft})$ and $3.7 \mathrm{~m} \mathrm{(12}$

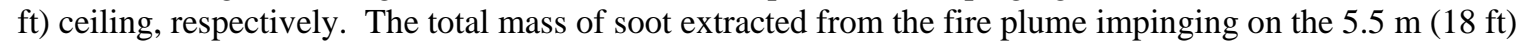
ceiling could not be reliably quantified. The much lower soot deposition on the $5.5 \mathrm{~m}$ ceiling was a result of the greater dilution of the soot concentrations due to an increase in air entrainment into the plume compared to the lower ceiling heights. Considering the $11.9 \mathrm{~g}$ soot loss for the $2.7 \mathrm{~m} \mathrm{(9} \mathrm{ft)} \mathrm{ceiling} \mathrm{height,} \mathrm{when}$ compared to the total mass of soot released by the burning fuel for a constant $100 \mathrm{~kW}$ propylene fire burning for 5 minutes (i.e., $30.7 \mathrm{~g}$ ) it was determined that approximately $39 \%$ of the soot was removed from the plume before transitioning into the ceiling jet. Similarly, approximately $33 \%$ of the soot contained

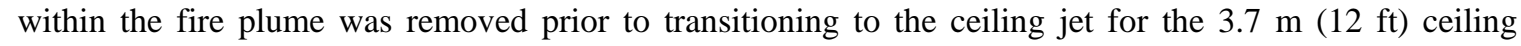
height.

Fig. 11 shows that the fairly close agreement between the measured smoke levels from a fire with a soot yield of 4.8 percent compared to the 2006 model predictions for a fuel with a yield of 2.2 percent. Assuming equivalent smoke levels down the corridor ceiling, the experimental to modeling comparison would indicate that 54 percent (i.e., 1 - 2.2/4.8) of the fuel produced soot is lost between the fire and the $4.6 \mathrm{~m}$ measuring location down the length of the ceiling. Therefore, the measured assessment of up to 
37 percent soot loss at the plume impingement area is reasonable. Observations of soot buildup down the ceiling over the course of testing indicated additional soot loss beyond the plume impingement area. However, observations clearly indicated that the bulk of soot deposition was in the plume impingement area on the ceiling.

Overall, these findings certainly show a need for further study of soot deposition in fires. The experimental results and the process of quantifying the soot loss have identified a number of considerations and difficulties in obtaining accurate soot deposition measurements. The comparison of experimental and FDS predicted smoke concentrations has also shown the degree of impact that soot loss to surfaces can have relative to smoke concentration and smoke detection response calculations.

\section{CONCLUSIONS}

A 2006 Fire Protection Research Foundation (FPRF) project used the NIST Fire Dynamics Simulator, version 4, to investigate smoke detector spacing for spaces with deep beam pockets and level ceilings. One configuration evaluated in this research was a corridor configuration with varying beam depth, beam spacing, corridor width, and ceiling height. A subset of the modeled corridor configurations was conducted with full-scale experiments to validate the findings of the modeling study. This paper presents the findings of the experimental validation and new discoveries regarding smoke production and loss mechanisms that have an impact on modeling of fires and the spread of smoke. The steady-state temperature and velocity measurements along the corridor ceiling were consistent with the modeling results. However, the work revealed that there was a large difference in the measured smoke concentration down the length of the corridor compared to the model predictions. The model over-predicted smoke levels by a factor of 2 to 5 times the measured values. This large discrepancy is attributed to soot losses on the ceiling. Exploratory findings indicate that soot deposits to the ceiling above the plume may be as high as 39 percent of the soot produced. This estimate only includes the circular impact area of the plume on the ceiling and not additional losses that may occur between the ceiling jet and the ceiling and wall surfaces. Current versions of FDS and most fire models do not account for this substantial soot loss. Certainly there is a need for further study of soot deposition in fires, particularly as it relates to smoke detector response and smoke concentration calculations.

Another important finding of this work was a large discrepancy between reported small-scale soot yields and yields from larger scale fires. Commonly used soot yields in the literature for a range of fuel materials have been obtained for small fires conducted in bench-scale calorimetry apparatus. This work has shown that measured soot yields for $100 \mathrm{~kW}$ fires range from 2 to 5 times smaller than the reported values. This finding is consistent with other data in the literature; however, there are minimal published studies that address this issue.

\section{ACKNOWLEDMENTS}

This work was conducted under a grant from the Fire Protection Research Foundation (FPRF) for the project, "Smoke Detector Spacing Requirements for Complex Beamed and Sloped Ceilings."

\section{REFERENCES}

[1] O’Connor, D., Cui, E., Klaus, M., et. al, “Smoke Detector Performance for Level Ceilings with Deep Beams and Deep Beam Pocket Configurations, An Analysis Using Computational Fluid Dynamics,” National Fire Protection Research Foundation, Quincy, MA, 2006.

[2] McGrattan, K., Forney, G. (2005), “Fire Dynamics Simulator (Version 4) User’s Guide,” NIST Technical Special Publication 1019, National Institute of Standards and Technology, Gaithersburg, MD.

[3] McGrattan, K. (2005), "Fire Dynamics Simulator (Version 4) Technical Reference Guide,” NIST Technical Special Publication 1018, National Institute of Standards and Technology, Gaithersburg, MD.

[4] ANSI/UL 268-2006, "Standard for Smoke Detectors for Fire Alarm Signaling Systems," Fifth Edition dated September 8, 2006, Underwriters Laboratories Inc., Northbrook, IL. 
[5] ISO 9705, "Fire tests - Full-scale room test for surface products," International Standards Organization, 1996.

[6] Tewarson, "Generation of Heat and Chemical Compounds in Fire," The SFPE Handbook of Fire Protection Engineering ( $3^{\text {rd }}$ ed), DiNenno P.J. (ed.), National Fire Protection Association, Quincy, MA 02269, 2002, p. 3/4.

[7] ASTM E2058-06, "Standard Test Methods for Measurement of Synthetic Polymer Material Flammability Using a Fire Propagation Apparatus,” ASTM International, 2007.

[8] Pitts, W.M. and Mulholland, G.W., "Improved Real-Scale Fire Measurements Having Meaningful Uncertainty Limits,” NISTIR 6588, National Institute of Standards and Technology, Gaithersburg, MD, November 2000.

[9] Mealy, C., Riahi, S., Floyd, J., Gottuk, D., "Smoke Detector Spacing Requirements Complex Beamed and Sloped Ceilings - Volume 1: Experimental Validation of Smoke Detector Spacing Requirements," Fire Protection Research Foundation, Quincy, MA, 2008.

[10] Zukoski, E.E., "Properties of Fire Plumes," Combustion Fundamentals of Fire, (G.Cox, ed.) New York, Academic Press, 1995, pp. 101-219.

[11] Drysdale, D., An Introduction to Fire Dynamics, $2^{\text {nd }}$ Edition, Wiley, 1998.

[12] McGratten, K. (2008), “Fire Dynamics Simulator (Version 5) Technical Reference Guide,” NIST Technical Special Publication 1018-5, National Institute of Standards and Technology, Gaithersburg, MD.

[13] Butler, K.M., and Mulholland, G.W., "Generation and Transport of Smoke Components," Fire Technology, 40, pp. 149-176. 2004. http://dx.doi.org/10.1023/B:FIRE.0000016841.07530.64 